\title{
Metabolic syndrome signs in Wistar rats submitted to different high-fructose ingestion protocols
}

\author{
Rodrigo Ferreira de Moura ${ }^{1}$, Carla Ribeiro ${ }^{1}$, Juliana Aparecida de Oliveira ${ }^{2}$, Eliane Stevanato ${ }^{2}$ and \\ Maria Alice Rostom de Mello ${ }^{1 *}$ \\ ${ }^{1}$ Physical Education Department, São Paulo State University (UNESP), Avenida 24-A, 1515 Bela Vista, 13506-900 Rio Claro, \\ SP, Brazil \\ ${ }^{2}$ Physical Education Department, University of Taubaté (UNITAU), Rua Terras de Cambra 27, 04383-145 São Paulo, SP, Brazil
}

(Received 7 January 2008 - Revised 17 July 2008 - Accepted 18 July 2008 - First published online 14 November 2008)

In search of an adequate model for the human metabolic syndrome, the metabolic characteristics of Wistar rats were analysed after being submitted to different protocols of high fructose ingestion. First, two adult rat groups (aged $90 \mathrm{~d}$ ) were studied: a control group $(\mathrm{C} 1 ; n 6)$ received regular rodent chow (Labina, Purina) and a fructose group $(\mathrm{F} 1 ; n 6)$ was fed on regular rodent chow. Fructose was administered as a $10 \%$ solution in drinking water. Second, two adult rat groups (aged $90 \mathrm{~d})$ were evaluated: a control group (C2;n 6) was fed on a balanced diet (AIN-93G) and a fructose group $(\mathrm{F} 2 ; n 6)$ was fed on a purified $60 \%$ fructose diet. Finally, two young rat groups (aged $28 \mathrm{~d}$ ) were analysed: a control group $(\mathrm{C} 3 ; n 6)$ was fed on the AIN-93G diet and a fructose group $(\mathrm{F} 3 ; n 6)$ was fed on a $60 \%$ fructose diet. After $4-8$ weeks, the animals were evaluated. Glucose tolerance, peripheral insulin sensitivity, blood lipid profile and body fat were analysed. In the fructose groups F2 and F3 glucose tolerance and insulin sensitivity were lower, while triacylglycerolaemia was higher than the respective controls $\mathrm{C} 2$ and $\mathrm{C} 3(P<0.05)$. Blood total cholesterol, HDL and LDL as well as body fat showed change only in the second protocol. In conclusion, high fructose intake is more effective at producing the signs of the metabolic syndrome in adult than in young Wistar rats. Additionally, diet seems to be a more effective way of fructose administration than drinking water.

Fructose: Metabolic syndrome: Insulin sensitivity: Body fat

Clinically, the metabolic syndrome involves a cluster of disturbances in which glucose intolerance represents an important symptom. Metabolic syndrome diagnosis implies in positive results to at least three metabolic alterations including insulin resistance, hypertension, obesity, endothelial dysfunction and blood lipid profile alterations ${ }^{(1,2)}$. These multiple risk factors accelerate the incidence of CVD in a cooperative way ${ }^{(1-4)}$.

Obesity prevalence has quadrupled in the past 25 years in the USA; $16 \%$ of children and $30 \%$ of adults are now affected and many of these obese individuals suffer from the metabolic syndrome ${ }^{(5)}$. Projections estimate that, in the year 2010, there will exist 50-75 million individuals with manifestation of this syndrome in this country alone ${ }^{(6)}$.

The increased fructose consumption in contemporaneous Western society has been associated with the high prevalence of non-alcoholic fatty liver disease (NAFLD) ${ }^{(7)}$, obesity, type 2 diabetes and metabolic syndrome so far ${ }^{(8,9)}$. In fact, laboratory animals fed on fructose-rich diets show glucose intolerance, insulin resistance, hyperinsulinaemia and dyslipidaemia ${ }^{(10)}$. A high flux of fructose to the liver perturbs glucose metabolism and glucose uptake pathways, and leads to a significantly enhanced rate of lipogenesis and TAG synthesis, driven by the high flux of glycerol and acyl portions of TAG molecules from fructose catabolism ${ }^{(11-13)}$. These metabolic disturbances maybe underlie the induction of insulin resistance, commonly observed with high fructose feeding in both human subjects and animal models ${ }^{(14)}$. Since fructose-fed rats reveal signs of the metabolic syndrome, they are used as an experimental model of the human condition ${ }^{(15)}$.

The metabolic alterations observed in fructose-fed rats are quite divergent among the studies, probably due to study design. Differences between studies include: the strain of rat used, such as Wistar ${ }^{(16,17)}$ and Sprague-Dawley ${ }^{(18,19)}$; the amount and route of fructose administration - diet $(60 \%)^{(16,19)}$, oral administration $(8 \mathrm{~g} / \mathrm{kg})^{(17)}$ or drinking water $(10 \%)^{(19)}$; the age of the animals at the beginning of the experiment - young ${ }^{(16,17)}$ or adults ${ }^{(19)}$. Also, the period of fructose administration applied has been non-standard: from $4^{(17)}, 6^{(18)}$ or 8 weeks ${ }^{(19)}$ or during several months ${ }^{(18)}$. Natural variation of the control diet is another potential problem of animal studies. It can be a particular problem with non-purified diets, but the use of synthetic diets is largely described in the literature ${ }^{(20)}$. Therefore, different experimental designs for fructose administration in rats induce variable degrees of physiological responses.

Abbreviations: C1, experiment 1 control group; C2, experiment 2 control group; C3, experiment 3 control group; F1, experiment 1 fructose group; F2, experiment 2 frustose group; F3, experiment 3 fructose group; NAFLD, non-alcoholic fatty liver disease. 
In the search of an adequate experimental model to simulate the human metabolic syndrome, the present study was designed to analyse the metabolic characteristics of Wistar rats submitted to high fructose ingestion by different protocols.

\section{Methods}

Animal care and experimental design

Male Wistar rats were obtained from the São Paulo State University (UNESP Central Bioterium, Botucatu Campus, SP, Brazil). The rats were kept in a room with the temperature set to $25 \pm 1{ }^{\circ} \mathrm{C}$ and with a photoperiod of $12 \mathrm{~h}-12 \mathrm{~h}$ at the Physical Education Department Biodynamic laboratory of UNESP (Rio Claro campus, São Paulo, Brazil). Free access to water and food was provided. All experiments were performed in accordance with the European Convention for the Protection of Vertebrate Animals used for Experimental and other Scientific Purposes (Council of Europe no. 123, Strasbourg 1985).

The animals were separated at random and the studies were carried out in three separated series of experiments. In the first, two groups of adult rats were studied: the control group $(\mathrm{C} 1 ; n 6)$ received regular rodent chow $(57.3 \%$ carbohydrate, $41.2 \%$ as starch, Labina; Purina, São Paulo, Brazil) and the fructose group $(\mathrm{F} 1 ; n 6)$ was fed on a regular rodent chow and $10 \%$ of drinking water was composed of fructose solution. Both groups started the experiment aged $90 \mathrm{~d}$ and the follow-up was done for 8 weeks.

In the second experiment, two groups of adult rats were also evaluated: the control group $(\mathrm{C} 2 ; n 6)$ was fed on a purified balanced diet (AIN-93G) ${ }^{(21)}$ and a fructose group (F2;n 6) was fed on a purified $60 \%$ fructose diet (Table 1). Both groups started the experiment at age $90 \mathrm{~d}$ and the follow-up was done for 4 weeks.

Two groups of young rats were analysed in the third experiment: the control group $(\mathrm{C} 3 ; n 6)$ was fed on a balanced AIN$93 \mathrm{G}$ diet and the fructose group $(\mathrm{F} 3 ; n 6)$ was fed on a $60 \%$ fructose diet. Both groups started the experiment at age $28 \mathrm{~d}$ and the follow-up was done for 8 weeks.

All animals were weighed and measured (nose to anus length) once per week. At the end of the experimental period, the Lee index was calculated ${ }^{(22)}$ (by dividing the cubic root of the final body weight $(\mathrm{g})$ by the final body length $(\mathrm{cm})$ and multiplying by 1000). This index for rats is equivalent to the human BMI.

Table 1. Composition of the balanced and fructose-rich diets

\begin{tabular}{lcc}
\hline Ingredient (g/kg) & AIN-93G & Fructose diet \\
\hline Casein & 202 & 202 \\
Maize starch & 397 & - \\
Dextrinised maize starch & $130 \cdot 5$ & - \\
Sucrose & 100 & 27.5 \\
Fructose & - & 600 \\
L-Cysteine $_{\text {Soyabeans }}$ & 3 & 3 \\
Mineral mix (AIN-93G)* & 70 & 70 \\
Vitamin mix (AIN-93)* & 35 & 35 \\
Fibre & 10 & 10 \\
Choline chlorhydrate & 50 & 50 \\
\end{tabular}

${ }^{*}$ See Reeves et al. ${ }^{(21)}$.
The vessels containing the diets and the bottle of water were refilled each $2 \mathrm{~d}$. Once per week, the differences between the full vessels or full bottles and the content $24 \mathrm{~h}$ later were considered as the amount consumed and were registered. The average amount of fructose ingested was calculated as $60 \%$ of diet (experiments 2 and 3 ) or $10 \%$ of the water ingested during the whole period (experiment 1).

\section{Oral glucose tolerance test}

At the end of each experiment, the rats were fasted for $15 \mathrm{~h}$. Glucose was administered into the stomach of the rats through a gastric catheter at the final dose of $2.0 \mathrm{~g} / \mathrm{kg}$ body weight. Blood samples for serum glucose determination were obtained from a cut at the tip tail at 0, 30, 60 and $120 \mathrm{~min}$. Serum glucose determination was made by the glucose oxidase method (Laborlab Kit; Guarulhos, SP, Brazil) ${ }^{(23)}$. The glycaemic response during the oral glucose tolerance test was evaluated by the total area under the serum glucose curve using the trapezoidal method ${ }^{(24)}$.

\section{Subcutaneous insulin tolerance test}

At the end of all experimental series, subcutaneous insulin tolerance tests were performed for peripheral insulin sensitivity evaluation. The insulin tolerance tests consisted of a bolus injection of regular insulin at the dorsal region $(30 \mathrm{mU} / \mathrm{g}$ body weight). Blood samples were obtained from a cut at the tip tail at $0,30,60$ and 120 min for serum glucose determination by the glucose oxidase method (Laborlab Kit) ${ }^{(23)}$. A constant for serum glucose disappearance (Kitt) was calculated from the formula $0 \cdot 693 / t_{1 / 2}$. The serum glucose $t_{1 / 2}$ was calculated from the slope of the least square analysis of serum glucose concentration from $0-30 \mathrm{~min}$ after insulin injection, when serum glucose concentration decreased linearly ${ }^{(25)}$.

\section{Blood chemistry and body fat}

Because of multiple aspects involving insulin sensitivity evaluation, the fasting insulin concentration was also assessed.

All animals were killed by decapitation and trunk blood was collected for serum TAG, total cholesterol, HDL-cholesterol, LDL-cholesterol and glucose determinations by colorimetric procedures $^{(26)}$. Retroperitoneal, mesenteric (visceral) and subcutaneous posterior fat depots were excised and weighed according to $\mathrm{Cinti}^{(27)}$. Liver total lipid concentration ${ }^{(26)}$ was also determined.

\section{Statistics}

In each experiment, the values of weight and body length throughout the period of dietary intake were analysed by two-way ANOVA. All the other results were analysed statistically by the unpaired Student's $t$ test. A level of $5 \%$ was taken for statistical significance.

\section{Results}

The weight and body-length values in the first experiment are shown in Fig. 1. No difference was revealed. 

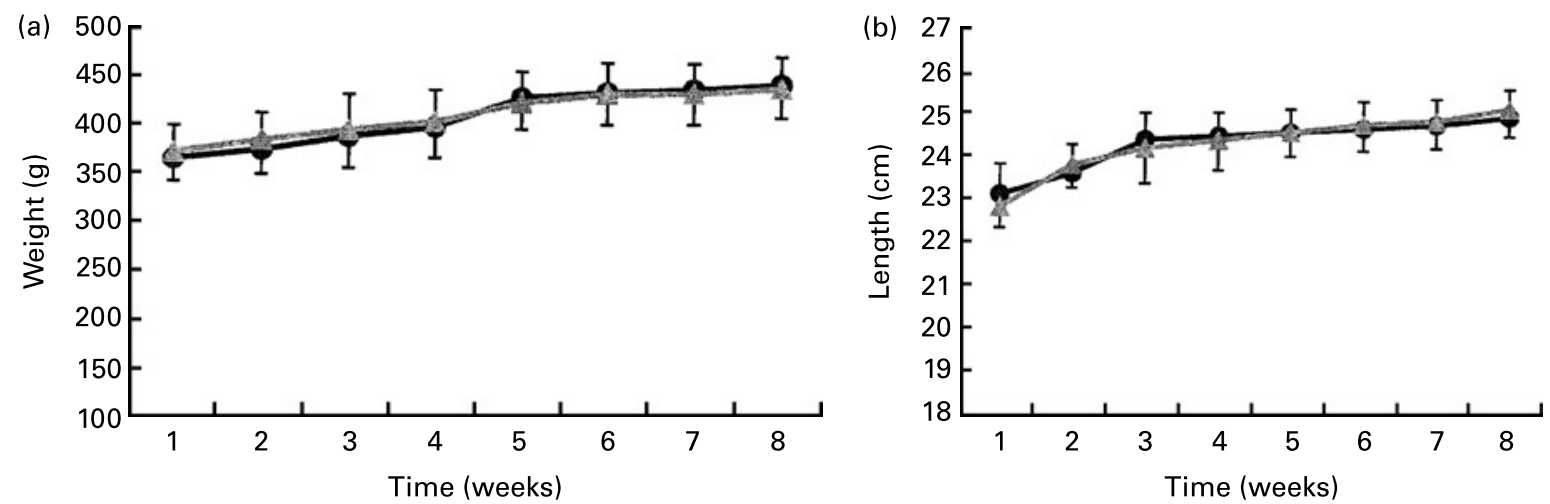

Fig. 1. Weight (a) and length (b) of fructose-fed (- $\left.\mathbf{A}^{-}\right)$and control $(-\bullet-)$ animals in the first experiment $(P>0.05)$.

Data from the first series are displayed in Table 2. No metabolic difference was observed between control (C1) and fructose-fed (F1) rats in any of the parameters evaluated. The average amount of fructose ingested corresponded to $1.74 \mathrm{~g} / 100 \mathrm{~g}$ body weight per $\mathrm{d}$.

No differences were observed in weight or body-length values in the second experiment (Fig. 2).

The data of the second experiment are shown in Table 3. The fructose group (F2) presented higher values for the area under the serum glucose curve during glucose tolerance tests when compared with the control group (C2). Rats of the F2 group developed insulin resistance when compared with the $\mathrm{C} 2$ group, indicated by a lower constant for serum glucose disappearance (Kitt) value and a higher fasting insulin concentration. No difference was observed in the basal serum glucose values between the two groups. Serum total cholesterol, HDL, LDL and TAG were higher in the F2 group than in the $\mathrm{C} 2$ group. In this experiment higher retroperitoneal, mesenteric and subcutaneous fat depot weights were observed in the F2 group in comparison with the $\mathrm{C} 2$ group. The concentration of liver total lipids was also higher in the F2 group compared with the $\mathrm{C} 2$ group. No difference was found between the groups in the results related to the Lee index. The average amount of fructose ingested in this second experiment was $2.70 \mathrm{~g} / 100 \mathrm{~g}$ body weight per $\mathrm{d}$.

No difference was observed in weight or body-length values in the third experiment (Fig. 3).

Table 4 shows data from the third series of experiments. The area under the serum glucose curve during glucose tolerance tests and TAG concentration were higher for the F3 group when compared with the C3 group. No differences were observed between the groups in insulin resistance, serum total cholesterol, basal glucose, HDL, LDL, retroperitoneal, mesenteric and subcutaneous fat depot weights and the Lee index. In this third experiment, the average amount of fructose ingested was $3.75 \mathrm{~g} / 100 \mathrm{~g}$ body weight per $\mathrm{d}$.

\section{Discussion}

There has been clinical and epidemiological evidence suggesting a progressive association of metabolic syndrome development and high fructose consumption ${ }^{(28)}$. Indeed, a marked increase in obesity and metabolic syndrome

Table 2. Effects of 8 weeks of fructose feeding as $10 \%$ solution in drinking water in adult male Wistar rats (experiment 1$)^{*}$ (Mean values and standard deviations of six animals per group)

\begin{tabular}{|c|c|c|c|c|}
\hline \multirow{2}{*}{$\begin{array}{l}\text { Group... } \\
\text { Parameter }\end{array}$} & \multicolumn{2}{|c|}{ Control (C1) } & \multicolumn{2}{|c|}{ Fructose (F1) } \\
\hline & Mean & SD & Mean & SD \\
\hline Area under serum glucose curve during GTT $(\mathrm{mM} \times 120 \mathrm{~min})$ & $1084 \cdot 0$ & $187 \cdot 3$ & 1124.9 & $99 \cdot 6$ \\
\hline Kitt (\%/min) & 0.60 & 0.27 & 0.61 & 0.48 \\
\hline Fasting insulin $(\mu \mathrm{U} / \mathrm{ml})$ & 4.09 & 0.54 & $4 \cdot 16$ & 0.63 \\
\hline Serum glucose $(\mathrm{mm})$ & $5 \cdot 7$ & 0.6 & 5.4 & 0.7 \\
\hline Serum total cholesterol (mM) & $2 \cdot 19$ & 0.48 & $2 \cdot 38$ & 0.44 \\
\hline Serum HDL-cholesterol (mM) & 1.64 & 0.26 & 1.82 & $0 \cdot 16$ \\
\hline Serum LDL-cholesterol (mM) & 0.49 & 0.23 & 0.63 & 0.37 \\
\hline Serum TAG (mм) & 1.90 & 0.64 & 1.82 & 0.67 \\
\hline Retroperitoneal fat depot weight $(\mathrm{mg} / 100 \mathrm{~g} \mathrm{bw})$ & $533 \cdot 7$ & 233.2 & 572.5 & $155 \cdot 0$ \\
\hline Mesenteric fat depot weight $(\mathrm{mg} / 100 \mathrm{~g} \mathrm{bw})$ & 651.5 & 139.9 & $697 \cdot 8$ & $167 \cdot 6$ \\
\hline Subcutaneous posterior fat depot weight ( $\mathrm{mg} / 100 \mathrm{~g} \mathrm{bw})$ & 514.4 & 171.5 & $521 \cdot 2$ & 94.1 \\
\hline Liver total lipids $(\mathrm{mg} / 100 \mathrm{mg})$ & $5 \cdot 35$ & 0.94 & $5 \cdot 23$ & 0.57 \\
\hline Lee index & $318 \cdot 6$ & $10 \cdot 8$ & $316 \cdot 6$ & $10 \cdot 0$ \\
\hline
\end{tabular}

GTT, glucose tolerance test; Kitt, constant for serum glucose disappearance; bw, body weight.

${ }^{*}$ See Methods for details of the diets. 

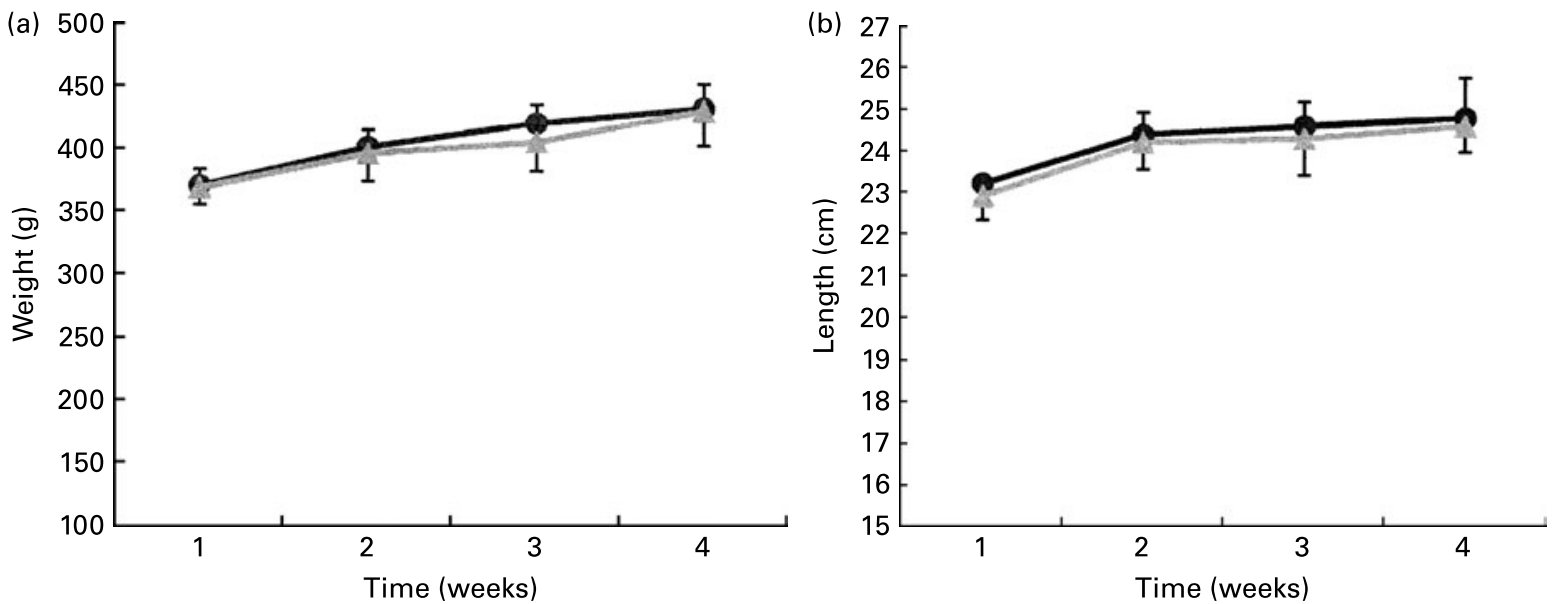

Fig. 2. Weight (a) and length (b) of fructose-fed (- $\left.\mathbf{A}^{-}\right)$and control $\left(-\mathbf{-}_{-}\right)$animals in the second experiment $(P>0 \cdot 05)$.

prevalence has been linked to a $30 \%$ overall increase in fructose ingestion in the last 20 years within the USA. It has been associated with the introduction of high-fructose maize syrup as a sweetener in soft drinks and other foods ${ }^{(5)}$. In the present study, we examined the effect of three different protocols of fructose administration on the metabolic characteristics of Wistar rats.

In the first protocol, fructose $(10 \%)$ was administered to adult $(90 \mathrm{~d})$ male Wistar rats in drinking water during 8 weeks. No metabolic differences were observed between the control and fructose-fed rats. Using the same procedure, Sanchez-Lozada et al. ${ }^{(19)}$ reported that fructose administration was able to induce systemic hypertension, hyperuricaemia and hypertriacylglycerolaemia in adult male Sprague-Dawley rats. Roglans et al. ${ }^{(29)}$ reported hypertriacylglycerolaemia and hepatic steatosis in Sprague-Dawley rats (the authors neither mention the age nor the weight of the animals at the beginning of the experiment) that had received fructose $(10 \%)$ in drinking water for 2 weeks. Additionally, while adult Sprague-Dawley rats fed fructose through drinking water developed features of the metabolic syndrome, adult Wistar rats presented a serum biochemical profile considered to be healthier for the cardiovascular system. Thus, the reported differences may be associated with the rat lineage used. In fact, Wistar rats seem to be less affected by the deleterious effects of fructose when administered in drinking water than Sprague-Dawley ones.

Sanchez-Lozada et al. ${ }^{(19)}$ compared the metabolic effects of fructose $(10 \%)$ in drinking water and a high-fructose $(60 \%)$ diet in Sprague-Dawley rats. Both procedures induced hyperuricaemia and hypertriacylglycerolaemia. However, the $60 \%$ fructose diet resulted in a higher fructose energy intake, which was directly associated with worsening metabolic syndrome parameters. Other studies have also reported hyperinsulinaemia, hypertriacylglycerolaemia and glucose intolerance in Sprague-Dawley rats fed on $60 \%$ fructose diets from 4 to 7 weeks ${ }^{(11,12,17,18,30-32)}$. Thus, in the second experiment series, a fructose diet was administered to adult male Wistar rats (age $90 \mathrm{~d}$ ) for 4 weeks.

Table 3. Effects of 4 weeks of feeding a $60 \%$ fructose diet in adult male Wistar rats (experiment 2) $\dagger$ (Mean values and standard deviations of six animals per group)

\begin{tabular}{|c|c|c|c|c|}
\hline \multirow{2}{*}{$\begin{array}{l}\text { Group... } \\
\text { Parameter }\end{array}$} & \multicolumn{2}{|c|}{ Control (C2) } & \multicolumn{2}{|c|}{ Fructose (F2) } \\
\hline & Mean & SD & Mean & SD \\
\hline Area under serum glucose curve during GTT $(\mathrm{mM} \times 120 \mathrm{~min})$ & 862.5 & $80 \cdot 4$ & $951 \cdot 4^{*}$ & $106 \cdot 8$ \\
\hline Kitt $(\% / \min )$ & 0.73 & 0.16 & $0.47^{\star}$ & 0.16 \\
\hline Fasting insulin $(\mu \mathrm{U} / \mathrm{ml})$ & 4.04 & 0.93 & $4.91^{*}$ & 1.42 \\
\hline Serum glucose (mм) & 6.83 & 0.93 & $6 \cdot 33$ & 1.3 \\
\hline Serum total cholesterol (mM) & $2 \cdot 54$ & $0 \cdot 16$ & $5 \cdot 82^{*}$ & 1.92 \\
\hline Serum HDL-cholesterol (mм) & 0.78 & 0.17 & $1.08^{*}$ & 0.16 \\
\hline Serum LDL-cholesterol (mм) & 0.51 & $0 \cdot 19$ & $0.74^{*}$ & 0.20 \\
\hline Serum TAG (mM) & $1 \cdot 28$ & 0.44 & $2 \cdot 55^{\star}$ & 0.84 \\
\hline Retroperitoneal fat depot weight (mg/100 g bw) & $598 \cdot 2$ & 173.9 & $873.9^{\star}$ & 347.9 \\
\hline Mesenteric fat depot weight $(\mathrm{mg} / 100 \mathrm{~g} \mathrm{bw})$ & 659.9 & $191 \cdot 2$ & $999 \cdot 9^{*}$ & 263.8 \\
\hline Subcutaneous posterior fat depot weight ( $\mathrm{mg} / 100 \mathrm{~g} \mathrm{bw})$ & 429.5 & 197.9 & $640 \cdot 4^{*}$ & 203.6 \\
\hline Liver total lipids ( $\mathrm{mg} / 100 \mathrm{mg}$ ) & 5.4 & 0.3 & $9 \cdot 70^{*}$ & $4 \cdot 0$ \\
\hline Lee index & 294.3 & $6 \cdot 3$ & $296 \cdot 8$ & $7 \cdot 8$ \\
\hline
\end{tabular}

GTT, glucose tolerance test; Kitt, constant for serum glucose disappearance; bw, body weight. ${ }^{*}$ Mean value was significantly different from that of the control group $(P<0.05$; unpaired $t$ test). †For details of the diets, see Methods. 

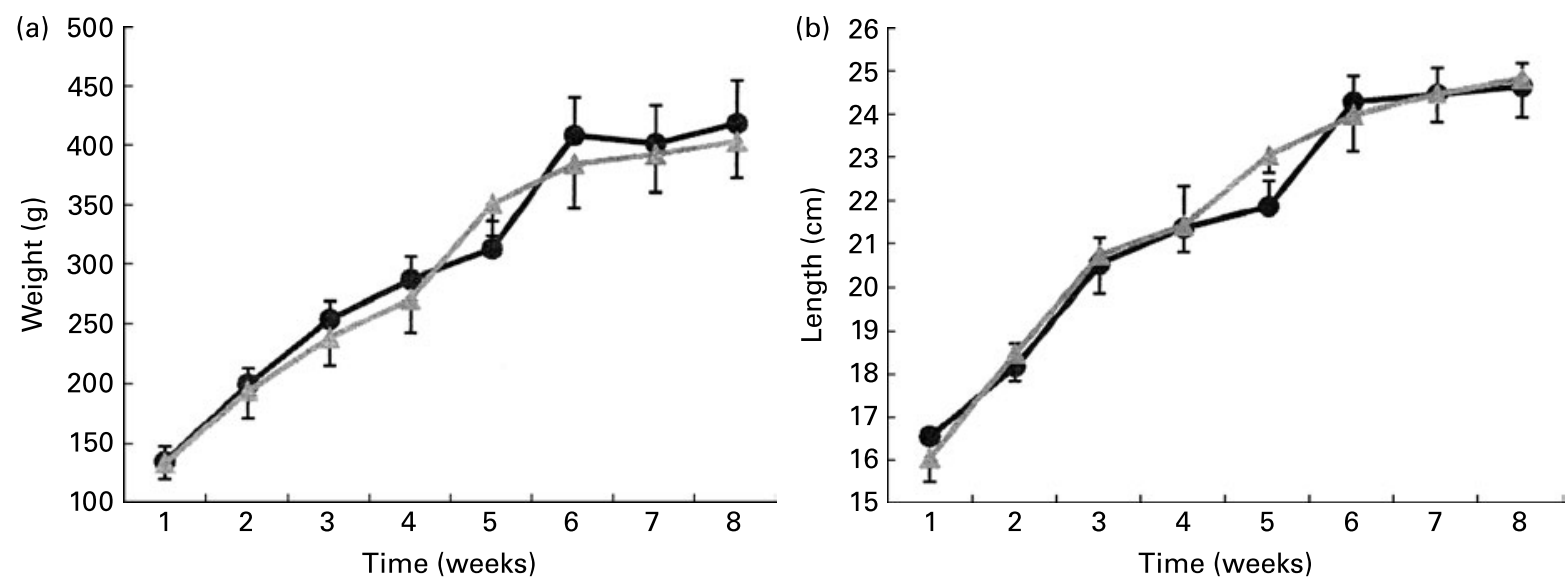

Fig. 3. Weight (a) and length (b) of fructose-fed $\left(-\mathbf{A}^{-}\right)$and control $(-\bullet-)$ animals in the third experiment $(P>0.05)$

Using the fructose-rich diet protocol, we also succeeded in inducing signs of the metabolic syndrome in fructose-fed Wistar rats, such as glucose intolerance, insulin resistance and high serum TAG, total cholesterol and LDL as well as a high concentration of total liver lipids.

The elevated liver lipid accumulation is the sign of NAFLD that may contribute to the development of non-alcoholic steatohepatitis $^{(33)}$ in individuals who do not consume significant amounts of ethanol ${ }^{(34)}$. This result reinforces the assumption that not only high-fat dietary consumption plays a role in NAFLD, but also high fructose ingestion. In this way, Ouyang et al. ${ }^{(35)}$ showed that fructose ingestion in patients with NAFLD was 2- to 3-fold higher than in control groups.

It has been reported that adult Sprague-Dawley rats given fructose solution with standard diets gained more weight and had significantly more fat tissue weight than control rats given only a standard $\operatorname{diet}^{(36)}$. Alterations in body fat were also observed in the fructose-fed rats of the second experiment, which showed retroperitoneal, mesenteric and subcutaneous fat depot weight increase.

Lau et al. ${ }^{(37)}$, in a prospective study with non-diabetic patients, found no association between the glycaemic index or glycaemic load of the diet with the probability of developing insulin resistance. Barbosa et al. ${ }^{(17)}$ compared the effects of glucose and fructose supplementation $(8 \mathrm{~g} / \mathrm{kg})$ in Wistar rats during 3 weeks. The authors reported insulin resistance and hypertriacylglycerolaemia in response to both treatments, but the glycaemia was higher in the fructose group. The fructose glycaemic index is about 3-fold lower than glucose and therefore the alterations observed may not be related to this index or even to glycaemic load (glycaemic index multiplied by amount in grams). In addition, the second experiment, which revealed more damage to the rats, presented just an intermediate value of daily fructose ingested in comparison with the first and third experiments.

The third experiment series was designed to analyse the metabolic alterations caused in young $(28 \mathrm{~d})$ Wistar rats by administration of a high-fructose diet for 8 weeks. The young animals fed on the high-fructose diet showed hypertriacylglycerolaemia and glucose intolerance in the absence of alterations in insulin sensitivity, serum total cholesterol, LDL and HDL concentration as well as mesenteric, retroperitoneal and subcutaneous fat depot weights when compared with the control group. In contrast, insulin sensitivity

Table 4. Effects of 8 weeks of feeding a $60 \%$ fructose diet in young male Wistar rats (experiment 3) $\dagger$

(Mean values and standard deviations of six animals per group)

\begin{tabular}{|c|c|c|c|c|}
\hline \multirow{2}{*}{$\begin{array}{l}\text { Group... } \\
\text { Parameter }\end{array}$} & \multicolumn{2}{|c|}{ Control (C3) } & \multicolumn{2}{|c|}{ Fructose (F3) } \\
\hline & Mean & SD & Mean & SD \\
\hline Area under serum glucose curve during GTT $(\mathrm{mM} \times 120 \mathrm{~min})$ & $1128 \cdot 1$ & $92 \cdot 6$ & $1246 \cdot 8^{*}$ & $69 \cdot 1$ \\
\hline Kitt (\%/min) & 0.62 & 0.23 & 0.65 & 0.37 \\
\hline Fasting insulin $(\mu \mathrm{U} / \mathrm{ml})$ & 4.18 & 0.55 & 4.07 & 0.61 \\
\hline Serum glucose $(\mathrm{mm})$ & $7 \cdot 12$ & 0.83 & 6.75 & 0.89 \\
\hline Serum total cholesterol (mM) & 2.47 & 0.58 & 3.01 & 0.50 \\
\hline Serum HDL-cholesterol (mM) & 0.98 & 0.27 & 1.09 & 0.3 \\
\hline Serum LDL-cholesterol (mM) & 0.79 & 0.33 & 0.83 & 0.43 \\
\hline Serum TAG (mм) & 0.68 & 0.19 & $1.09^{*}$ & 0.25 \\
\hline Retroperitoneal fat depot weight $(\mathrm{mg} / 100 \mathrm{~g} \mathrm{bw})$ & 713.7 & $290 \cdot 4$ & $764 \cdot 8$ & $228 \cdot 1$ \\
\hline Mesenteric fat depot weight (mg/100 g bw) & $762 \cdot 6$ & 237.7 & $782 \cdot 0$ & 143.5 \\
\hline Subcutaneous posterior fat depot weight ( $\mathrm{mg} / 100 \mathrm{~g} \mathrm{bw})$ & $772 \cdot 0$ & $356 \cdot 6$ & $696 \cdot 4$ & 249.5 \\
\hline Liver total lipids $(\mathrm{mg} / 100 \mathrm{mg})$ & 6.48 & 1.34 & $6 \cdot 80$ & 2.55 \\
\hline Lee index & $298 \cdot 8$ & $7 \cdot 6$ & 307.9 & $10 \cdot 7$ \\
\hline
\end{tabular}

GTT, glucose tolerance test; Kitt, constant for serum glucose disappearance; bw, body weight.

* Mean value was significantly different from that of the control group $(P<0.05$; unpaired $t$ test).

$\dagger$ For details of the diets, see Methods. 
impairment has been described in 5-week-old Wistar-Hannover rats, after $28 \mathrm{~d}$ of high-fructose diet ingestion associated with hypertriacylglycerolaemia and unchanged body-weight gain, basal serum glucose and serum total cholesterol ${ }^{(38)}$.

Interestingly, the third experiment showed that the average amount of daily fructose ingestion was almost $40 \%$ higher than in the second experiment, but did not induce a complete metabolic syndrome picture in these animals. A reasonable hypothesis could be the influence of protective mechanisms linked to youth in Wistar rats. However, further investigation will be necessary.

It is important to note that the AIN-93G provided in both series of experiments is recommended for the growth phase and is composed of $75 \%$ more fat and $42.9 \%$ more casein than an adult maintenance diet. However, the $\mathrm{C} 2$ rats presented fat depot values very similar to the $\mathrm{C} 1$ rats that ingested the regular rodent chow.

The dietary ingestion of fructose in humans is basically associated with soft drinks (whose sugars are composed of $45 \%$ of glucose and $55 \%$ of fructose), which account for just $8 \%$ of total energy intake ${ }^{(39)}$. However, Montonen et al. ${ }^{(40)}$ in a cohort-designed study reported that the risk of type 2 diabetes occurrence is 1.67 higher with this dietary profile. The emerging evidence from recent epidemiological and biochemical studies clearly suggests that the high fructose dietary intake has rapidly become an important causative factor in the development of the metabolic syndrome ${ }^{(8)}$.

Nevertheless, the present study was not designed to investigate fructose dose-response characteristics, as there are different metabolic responses to high-fructose diets even within rodents ${ }^{(17)}$. The importance of the present study resides in identifying the most adequate protocol to induce the metabolic syndrome in Wistar rats. According to the present findings, feeding adult rats $(90 \mathrm{~d})$ on a purified high-fructose $(60 \%)$ diet for 4 weeks seems to be an appropriate protocol for this purpose.

Concerning the limitations of the study, the lack of baseline values for the biochemical variables implies that already existent differences could have been missed. However, the randomisation process to compose the groups diminishes this possibility.

The absence of energy expenditure or physical activity measures does not exclude the possibility that the differences in the fat depots are related to lower physical or metabolic activity. Nonetheless, based on the randomisation assumption it would imply that the fructose diet plays a role in spontaneous physical activity. Additional studies may answer this question.

In conclusion, the results in the three series of experiments reveal that high fructose intake is more effective to produce signs of the metabolic syndrome in adult than in young Wistar rats, despite a shorter feeding period. Also, diet seems to provide a better effective route for fructose administration than drinking water.

\section{Acknowledgements}

The authors thank Clarice Y. Sibuya, Eduardo Custódio and José Roberto R. Silva for technical assistance. This research was supported by Brazilian foundations FAPESP (process:
07/54 098-0 and 05/57 741-6) and CNPQ (process: 30 027/ 2004-6). R. F. M was responsible for the statistical analysis and wrote the manuscript. C. R. was responsible for the biochemical analysis and was co-author of the manuscript. J. A. O. conducted study 1 . E. S. was responsible for designing and planning study 1. M. A. R. M. designed, planned and oversaw studies 2 and 3. All the authors read and agreed with the final format. The study authors have no conflict of interests.

\section{References}

1. Reaven GM (1988) Role of insulin resistance in human disease. Diabetes 37, 1595-1607.

2. Zecchin HG, Carvalheira JBC \& Saad MJA (2004) Mecanismos moleculares da resistência à insulina na síndrome metabólica (Molecular mechanisms of insulin resistance in the metabolic syndrome). Rev Soc Cardiol Est São Paulo 14, 574-589.

3. Fujioka S, Matsuzawa Y, Tokunaga K \& Tarui S (1987) Contribution of intra-abdominal fat accumulation to the impairment of glucose and lipid metabolism in human obesity. Metabolism 36, 54-59.

4. Kaplan NM (1989) The deadly quartet: upperbody obesity, glucose intolerance, hyperglycemia and hypertension. Arch Intern Med 149, 1514-1520.

5. Nakagawa T, Tuttle KR, Short RA \& Johnson RJ (2005) Hypothesis: fructose induced hyperuricemia as a causal mechanism for the epidemic of the metabolic syndrome. Nat Clin Pract Nephrol 1, 80-86.

6. Samad F, Uysal KT, Wiesbrock SM, Pandey M, Hotamisligil GS \& Loskutoff DJ (1999) Tumor necrosis factor $\alpha$ is a key component in the obesity-linked elevation of plasminogen activator inhibitor 1. Proc Natl Acad Sci U S A 96, 6902-6907.

7. Cave M, Deaciuc I, Mendez C, Song Z, Joshi-Barve S, Barve S \& McClain C (2007) Nonalcoholic fatty liver disease: predisposing factors and the role of nutrition. $J$ Nutr Biochem $\mathbf{1 8}$, 184-195.

8. Gross LE, Li L, Ford ES \& Liu S (2004) Increased consumption of refined carbohydrates and the epidemic of type 2 diabetes in the United States: an ecologic assessment. Am J Clin Nutr 79, 774-779.

9. Astrup A \& Finer N (2000) Redefining type 2 diabetes: 'diabesity' or 'obesity dependent diabetes mellitus'? Obes Rev 1 , $57-59$.

10. Hwang I-S, Ho H, Hoffman BB \& Reaven GM (1987) Fructoseinduced insulin resistance and hypertension in rats. Hypertension 10, 512-516.

11. Katakam PV, Ujhelyi MR, Hoenig ME \& Miller AW (1998) Endothelial dysfunction precedes hypertension in diet-induced insulin resistance. Am J Physiol 275, 788-792.

12. Kelley GL, Allan G \& Azhar S (2004) High dietary fructose induces a hepatic stress response resulting in cholesterol and lipid dysregulation. Endocrinology 145, 548-555.

13. Hallfrisch J (1990) Metabolic effects of dietary fructose. FASEB $J$ 4, 2652-2660.

14. Basciano H, Federico L \& Adeli K (2005) Fructose, insulin resistance, and metabolic dyslipidemia. Nutr Metab (Lond) 2, 5-18.

15. Okada Y, Yoshino T, Takeuchi A, Endoh M, Ohta H, Jinno Y, Yokoyama T, Izawa T \& Kobayshi E (2000) Effects of the $\mathrm{K}^{+}$ channel opener KRN4884 on the cardiovascular metabolic syndrome model in rats. J Cardiol Pharmacol 35, 287-293.

16. Joyeux-Faure M, Rossini E, Ribuot C \& Faure P (2006) Fructose-fed rat hearts are protected against ischemia-reperfusion injury. Exp Biol Med 231, 456-462. 
17. Barbosa CR, Albuquerque EMV, Faria EC, Oliveira HCF \& Castilho LN (2007) Opposite lipemic response of Wistar rats and C57BL/6 mice to dietary glucose or fructose supplementation. Braz J Med Biol Res 40, 323-331.

18. Lee YC, Ko YH, Hsu YP \& Ho LT (2006) Plasma leptin response to oral glucose tolerance and fasting/re-feeding tests in rats with fructose-induced metabolic derangements. Life Sci 78, $1155-1162$.

19. Sánchez-Lozada LG, Tapia E, Jiménez A, et al. (2007) Fructose-induced metabolic syndrome is associated with glomerular hypertension and renal microvascular damage in rats. Am J Physiol Renal Physiol 292, 423-429.

20. Daly ME, Vale C, Walke M, George K, Albert MM \& Mathers JC (1997) Dietary carbohydrates and insulin sensitivity: a review of the evidence and clinical implications. Am J Clin Nutr 66, 1072-1085.

21. Reeves PG, Nielsen HN \& Fahey GC (1993) AIN-93 purified diets for laboratory rodents: final report of the American Institute of Nutrition ad hoc writing committee on the reformulation of the AIN-76A rodent diet. $J$ Nutr 123, 1939-1951.

22. Bernardis LL \& Peterson BD (1968) Correlation between Lee index and carcass fat content in weaning and adult female rats with hypothalamic lesions. J Endocrinol 40, 527-528.

23. Latorraca MC, Carneiro EM, Boschero AC \& Mello MAR (1998) Protein deficiency during pregnancy and lactation impairs glucose-induced insulin secretion but increases the sensitivity to insulin in rats. Br J Nutr 80, 291-297.

24. Mathews JNS, Altaman DG, Campbell MJ \& Royston P (1990) Analysis of serial measurements in medical research. BMJ 27, 230-235.

25. Lundbaek K (1962) Intravenous glucose tolerance test as a tool in definition and diagnosis of diabetes mellitus. BMJ 2, $1507-1513$.

26. Nogueira DM, Strufaldi B, Hirata MH, Abdalla DSP \& Hirata RDC (1990) Sangue - parte I: glicídios (Blood - part 1: glycides). In Métodos de Bioquímica Clínica (Methods of Clinical Biochemistry), pp. 153-168 [Pancast editor]. São Paulo: Pancast.

27. Cinti S (2005) The adipose organ. Prostaglandins Leukot Essent Fatty Acids 73, 9-15.

28. Elliott SS, Keim NL, Stern JS, Teff K \& Havel PJ (2002) Fructose, weight gain, and the insulin resistance syndrome. Am J Clin Nutr 76, 911-922.
29. Roglans N, Vilà L, Farré M, Alegret M, Sánchez RM, VázquezCarrera M \& Laguna JC (2007) Impairment of hepatic Stat-3 activation and reduction of PPAR $\alpha$ activity in fructose-fed rats. Hepatology 45, 778-788.

30. Oron-Herman M, Rosenthal T, Mirelman D, Miron T, Rabinkov A, Wilchek M \& Sela B (2005) The effects of S-allylmercaptocaptopril, the synthetic product of allicin and captopril, on cardiovascular risk factors associated with the metabolic syndrome. Atherosclerosis 183, 238-243.

31. Sharabi Y, Oron-Herman M, Kamari Y, Avni I, Peleg E, Shabtay Z, Grossman E \& Shamiss A (2007) Effect of PPAR- $\gamma$ agonist on adiponectin levels in the metabolic syndrome: lessons from the high fructose fed rat model. Am J Hypertens 20, 206-210.

32. Wang X, Hattori Y, Satoh H, Iwata C, Banba N, Monden T, Konsuke U, Kamikawa Y \& Kasai K (2007) Tetrahydrobiopterin prevents endothelial dysfunction and restores adiponectin levels in rats. Eur J Pharmacol 555, 48-53.

33. Pitt HA (2007) Hepato-pancreato-biliary fat: the good, the bad and the ugly. $H P B$ (Oxford) 9, 92-97.

34. Zivkovi AC, Germam JB \& Sanyal AJ (2007) Comparative review of diets for the metabolic syndrome: implications for nonalcoholic fatty liver disease. Am J Clin Nutr 86, 285-300.

35. Ouyang X, Cirillo P, Sautin Y, McCall S, Bruchette JL, Diehl AM, Johnson RJ \& Abdelmalek MF (2008) Fructose consumption as a risk factor for non-alcoholic fatty liver disease. J Hepatol 48, 993-999.

36. Kanarek RB \& Orthen-Gambill N (1982) Differential effects of sucrose, fructose and glucose on carbohydrate-induced obesity in rats. $J$ Nutr 112, 1546-1554.

37. Lau C, Faerch K, Glümer C, Tetens I, Pedersen O, Carstensen B, Jorgensen T \& Borch-Johnsen K (2005) Dietary glycemic index, glycemic load, fiber, simple sugars, and insulin resistance. Diabetes Care 28, 1397-1403.

38. Bezerra RMN, Ueno M, Silva MS, Tavares DQ, Carvalho CRO, Saad MJA \& Gontijo JAR (2001) A high-fructose diet induces insulin resistance but not blood pressure changes in normotensive rats. Braz J Med Biol Res 34, 1155-1160.

39. Park YK \& Yetley EA (1993) Intakes and food sources of fructose in the United States. Am J Clin Nutr 58, 737S-747S.

40. Montonen J, Järvinen R, Knekt P, Heliövaara M \& Reunanen (2007) A consumption of sweetened beverages and intakes of fructose and glucose predict type 2 diabetes occurrence. J Nutr 137, 1447-1454. 